Marquette University

e-Publications@Marquette

College of Education Faculty Research and

Publications

Education, College of

$1-1-2009$

\title{
Toddlers with Developmental Delays and Challenging Behaviors
}

Kathryn M. Keller

Marquette University

Robert A. Fox

Marquette University, robert.fox@marquette.edu

Accepted version. Early Child Development and Care, Vol. 179, No. 1 (January 2009): 87-92. DOI. (C) 2009 Taylor \& Francis. Used with permission. 


\title{
Toddlers with Developmental Delays and Challenging Behaviors
}

\author{
Kathryn M. Keller \\ Counselor Education and Counseling Psychology \\ Marquette University \\ Milwaukee, WI \\ Robert Fox* \\ Counselor Education and Counseling Psychology \\ Marquette University \\ Milwaukee, WI
}

\begin{abstract}
Behavior problems and parental expectations and practices were studied in a sample of 58 toddlers with developmental disabilities who were consecutively referred to a mental health clinic. The majority of children (70.7\%) exceeded the clinical cut-off score for significant behavior problems including tantrums, aggression, defiance, and hyperactivity, and $77.6 \%$ met the DSM-IV criteria for a psychiatric diagnosis with oppositional defiant disorder being the most common. Consistent with previous research, child behavior problems were related to parental use of verbal and corporal punishment and were detrimental to the quality of the parent-child relationship. A new finding was that parental expectations also were positively related to the emergence of early child behavior problems.
\end{abstract}

\section{Introduction}

Children with developmental disabilities as young as two years of age show an increased risk for behavior problems compared with their same-aged, normally developing peers (Feldman et al., 2000). 
Comparing two samples of children with and without developmental delays, Baker et al. (2002) found that those with delays were three to four times more likely to score in the clinical range on a child behavior scale than children without delays. Moreover, these early behavior problems among toddlers with disabilities are likely to persist over time (Green et al., 2004), and may be further exacerbated when these children live in poverty (Aber et al., 2000).

Common behavior problems observed in young children that result in their referral to mental health programs (Gadow et al., 2001) include severe tantrums, aggression, non-compliance and hyperactivity. Rockhill et al. (2006) suggested that contributing factors to these early behavior problems fall into three major categories: child biological factors, including temperament; parent-child factors such as parenting practices; and contextual factors such as parental education, marital distress and poverty. Good longitudinal evidence is available that shows a child with a difficult temperament is at increased risk of having behavior problems (Thomas \& Chess, 1977). Regarding parenting and contextual factors, in a study of over 1000 urban mothers Fox et al. (1995) found less positive parenting practices (less nurturing and more frequent use of corporal and verbal punishment) among mothers who were younger, had more than one child living at home, were single and had lower income and educational levels. These mothers also reported more behavior problems in their young children. In a related study, Brenner and Fox (1998) found that parents' use of verbal and corporal punishment was the strongest single predictor of behavior problems in young children.

The present study extended these previous studies by examining parenting practices and behavior problems in young children, most of whom also had significant developmental delays. Similar to previous studies, these children came from families most of which were headed by single mothers living in poverty.

\section{Method}

\section{Participants}

The sample included 58 toddlers with significant behavior problems that were referred consecutively to a mental health clinic, designed specifically to address these concerns in this very young population (Fox et al., 2007). The average age of the children was 2.66 years (standard deviation $=0.72$ ), with $67 \%$ boys and $33 \%$ girls;

Early Child Development and Care, Vol. 179, No. 1 (2009): pg. 87-92. DOI. This article is (C) Taylor \& Francis (Routledge) and permission has been granted for this version to appear in e-Publications@Marquette. Taylor \& Francis (Routledge) does not grant permission for this article to be further copied/distributed or hosted elsewhere without the express permission from Taylor \& Francis (Routledge). 
$52 \%$ were African American, 21\% were Caucasian, 10\% were Latino and $17 \%$ were of mixed ancestry. The children were assessed through developmental screening and $77 \%$ met the criteria for a developmental disability, defined as being at least $25 \%$ delayed in one or more areas of development (e.g. motor, language, socialemotional); $30 \%$ of the children were born premature. The reasons for children being referred included temper tantrums (40\%), aggression (28\%), oppositional behavior (10\%), self-injury such as head banging (9\%) and hyperactivity (7\%), with the remaining $6 \%$ referred for a variety of issues including property destruction, separation anxiety and autistic-like characteristics. The primary caregiver was normally the biological mother ( $85 \%)$, most of whom were unemployed (56\%) and not married $(67 \%)$. The mean age of these mothers was 27.7 years (standard deviation $=6.2$ ), with the average mother having less than a high school education (mean $=11.7$ years, standard deviation $=$ 2.1) and with three children living in the home (range =1-13). Secondary caretakers (age: mean $=32.0$, standard deviation $=10.4$ ) included biological fathers, male partners and extended family members (grandparents, aunts, cousins and older siblings), most of whom were employed (65\%). The percentage of families living below the poverty level was 95\% (Health and Human Services, 2005).

\section{Intake evaluation}

As part of the intake evaluation, caregivers were administered the Eyberg Child Behavior Inventory (ECBI) (Eyberg \& Pincus, 1999) and the Parent Behavior Checklist (PBC) (Fox, 1994¹). The ECBI assesses 36 common problem behaviors in children and yields an intensity score (range $=36-252$ ) that measures the frequency of each behavior problem on a one (never) to seven (always) scale, and a total problem score (range $=0-36$ ) that assesses whether caregivers feel the behavior is a problem for them; the two ECBI scores have good internal consistency, test-retest reliability and inter-rater reliability for both scores. The PBC consists of 32 items divided among three scales that assess a parent's developmental expectations, nurturing and discipline (use of corporal and verbal punishment) for children one to four years of age; all three scales are internally consistent and have good test-retest reliability. At the conclusion of the intake evaluation, the Kiddie Schedule for Affective Disorders and Schizophrenia for School-Aged Children (K-SADS-PL) (Kaufman et al., 1997) was 
completed to determine whether or not the child met a diagnosis from the Diagnostic and Statistical Manual of Mental Disorders (DSM-IV) (American Psychiatric Association, 2000). The K-SADS-PL is a semistructured interview designed to assess current and past episodes of psychopathology in children. Finally, the Parent-Child Relationship Scale (Fox \& Nicholson, 2003) was completed, which provides a global assessment of the overall quality of the caregiver and child relationship on a scale of 0-100 with five behavioral anchors (poor relationship $=0-20$, average relationship $=45-60$ ) at 20-point intervals. Each anchor also includes descriptive statements to aid in appropriately classifying individual parents (good relationship: 'Parent is thoughtful when interacting with child', 'Parent expectations are usually appropriate', 'Parent is responsive to child's needs and sets appropriate limits on child's behavior', 'There is minimal evidence of verbal or corporal punishment', 'The parent-child relationship is very good').

\section{Results}

The raw scores for the instruments used during the intake evaluation are presented in Table 1 . Significant correlations (all $p<$ 0.05 ) were found between the PBC's expectations scores and the ECBI's intensity $(r=0.41)$ and problem scores $(r=0.49)$. That is, as parent's expectations increased, children's behavior difficulties increased in frequency, with more considered problematic by their caregivers. PBC discipline scores were positively related to expectations scores $(r=0.40)$ and negatively correlated with nurturing $(r=-0.32)$ and parent-child relationship scores $(r=-0.35)$. Parental use of verbal and corporal punishment was associated with higher expectations and lower nurturing practices, both of which had a negative impact on the quality of the parent-child relationship. The ECBI problem and intensity scores were highly related $(r=0.72)$. Total problem behavior scores on the ECBI increased with children's age $(r=0.32)$, as did parental use of corporal and verbal punishment as a form of discipline $(r=0.30)$. Finally, ECBI intensity scores were negatively related to the parent-child relationship scores $(r=-0.41)$.

Using the recommended cut-off $t$-score $\geq 60$ for clinical significance on the ECBI (Eyberg \& Pincus, 1999), $81.0 \%$ of the children in the sample met the cut-off value on the intensity scale and $70.7 \%$ met the cut-off value on the problem scale. Using a cut-off 
score of one standard deviation for the PBC scores (Fox, 1994), 17\% of the parents' expectations for their children were low and $29 \%$ were high; $10 \%$ had high discipline scores and $21 \%$ had low nurturing scores. Children received the following DSM-IV diagnoses: oppositional defiant disorder (56.9\%), conduct disorder (10.3\%), separation anxiety $(8.6 \%)$, attention deficit hyperactivity disorder $(1.7 \%)$ and no diagnosis (22.4\%). One-way analyses of variance were used to compare scores on the study's measures between children who received a DSM-IV diagnosis with children who did not. Raw scores were converted to standard $t$-scores for these analyses. Parents of children with a diagnosis reported higher expectations on the PBC (mean $=54.38)[F(1,56)=5.83, p=0.019]$ than parents of children without a diagnosis (mean $=45.08$ ). Similarly, parents of children with a diagnosis had higher scores on the ECBI's intensity (mean $=69.56$ ) $[F(1,56)=5.38, p=0.024]$ and problem scales (mean $=66.53)[F$ $(1,56)=4.14, p=0.047]$ than parents of children without a diagnosis (intensity mean $=62.77$; problem mean $=60.23$ ). There was a trend for the quality of the parent-child relationship to be less positive $[F(1,56)=3.45, p=0.068]$ for parents of children with a diagnosis (mean $=50.57$ ) compared with those without a diagnosis (mean $=59.58)$. These two groups of parents did not differ on their PBC nurturing ( $p=0.54)$ or discipline scores $(p=0.11)$.

\section{Discussion}

The sample included 58 toddlers consecutively referred to a mental health clinic for behavior problems. The majority of the sample had a developmental disability (77\%), with a boy: girl ratio of $2: 1$, and $77.6 \%$ met the diagnostic criteria in the DSM-IV for a psychiatric disorder. The majority had disruptive behavior disorders that can be accurately diagnosed with the DSM-IV at younger ages (Keenan \& Wakschlag, 2002).

As further evidence of these young children having significant behavior problems, $81.0 \%$ met the cut-off point on the ECBI intensity scale and $70.7 \%$ met the cut-off value on its problem scale, suggesting that these children were causing clinically significant problems for their caregivers (Eyberg \& Pincus, 1999). Behavior problems increased with the child's age, and as the frequency of problems increased so did the parents' management difficulties. Not surprisingly, the quality of the parent and child's relationship was 
negatively affected by the frequency of the child's behavior problems. Given the known trajectory of behavior problems in very young children (Campbell, 1995), in the absence of intervention these behaviors are unlikely to resolve on their own for many of these young children.

Parent scores on the PBC's expectations subscale emerged as a significant factor in this study. Previous research has found that parents of preschool-aged children with mild handicaps had lower expectations than parents of normally developing preschoolers (Tucker \& Fox, 1995). However, within the present sample where the majority of parents had a child with a disability, as parent expectations increased their children's behaviors became more problematic and frequent. Moreover, as parental expectations for their children increased, their use of verbal and corporal punishment increased and their use of positive nurturing strategies decreased, which seemed to have a detrimental impact on the quality of the parent-child relationship. Children who received a psychiatric diagnosis also had caregivers with higher expectations than children who did not. While the relationship between child behavior problems and parental use of verbal and corporal punishment as a form of discipline has been previously reported (Brenner \& Fox, 1998; Nicholson et al., 2005), the relationship between parent expectations and behavior problems in very young children with developmental disabilities has not been previously reported. Further research is needed to determine to what extent parental expectations and disciplinary practices contribute to the emergence and maintenance of behavior problems in young children with delays. This information would be helpful to the development of treatment programs designed to reduce behavior problems in very young children (Fox \& Nicholson, 2003).

\section{Acknowledgement}

- This research was supported in part by grants from the Assurant Health Foundation, Charles D. Jacobus Family Foundation, Exchange Club, Greater Milwaukee Foundation, and United Way.

\section{Notes}

- *Corresponding author. Email: Robert.fox@marquette.edu

- 1. Currently available from the corresponding author.

Early Child Development and Care, Vol. 179, No. 1 (2009): pg. 87-92. DOI. This article is (C) Taylor \& Francis (Routledge) and permission has been granted for this version to appear in e-Publications@Marquette. Taylor \& Francis (Routledge) does not grant permission for this article to be further copied/distributed or hosted elsewhere without the express permission from Taylor \& Francis (Routledge). 
NOT THE PUBLISHED VERSION; this is the author's final, peer-reviewed manuscript. The published version may be accessed by following the link in the citation at the bottom of the page.

\section{References}

Aber, J.L., Jones, S., \& Cohen, J. (2000). The impact of poverty on the mental health and development of very young children, in: C.H. Zeanah (Ed.) Handbook of infant mental health (2nd edn) (New York, Guilford Press), 113-128.

American Psychiatric Association (2000). Diagnostic and statistical manual of mental disorders (4th edn, text rev) (Washington, DC, APA).

Baker, B.L., Blacher, J., Crnic, K.A., \& Edelbrock, C. (2002). Behavior problems and parenting stress in families of three-year-old children with and without developmental delays, American Journal on Mental Retardation, 107, 433-444.

Brenner, V., \& Fox, R.A. (1998). Parental discipline and behavior problems in young children, The Journal of Genetic Psychology, 159, 251-256.

Campbell, S.B. (1995). Behavior problems in preschool children: a review of recent research, Journal of Child Psychology and Psychiatry, 36, 113149.

Eyberg, S.M., \& Pincus, D. (1999). Eyberg Child Behavior Inventory and the Sutter-Eyberg Student Behavior Inventory-revised (Lutz, FL, Psychological Assessment Resources, Inc.).

Feldman, M.A., Hancock, C.L., Rielly, N., Minnes, P., \& Cairns, C. (2000). Behavior problems in young children with or at risk for developmental delay, Journal of Child and Family Studies, 9, 247-261.

Fox, R.A. (1994). Parent behavior checklist (Austin, TX, ProEd).

Fox, R.A., \& Nicholson, B.C. (2003). Parenting young children: a facilitator's guide (Longmont, CO, Sopris West).

Fox, R.A., Platz, D.L., \& Bentley, K.S. (1995). Maternal factors related to parenting practices, developmental expectations, and perceptions of child behavior problems, The Journal of Genetic Psychology, 156, 431441.

Fox, R.A., Keller, K.M., Grede, P.L., \& Bartosz, A.M. (2007). A mental health clinic for toddlers with developmental delays and behavior problems, Research in Developmental Disabilities, 28, 119-129.

Gadow, K.D., Sprafkin, J., \& Nolan, E.E. (2001). DSM-IV symptoms in community and clinic preschool children, Journal of the American Academy of Child and Adolescent Psychiatry, 40, 1383-1392.

Green, V.A., O'Reilly, M.O., Itchon, J., \& Sigafoos, J. (2004). Persistence of early aberrant behavior in children with developmental disabilities, Research in Developmental Disabilities, 26, 47-55.

Health and Human Services (2005). The poverty guidelines updated periodically in the Federal Register by the U.S. Department of Health and Human Services under the authority of 42 U.S.C. 9902(2), Federal Register, 70, 8373-8375. 
Kaufman, J., Birmaher, B., Brent, D., Rao, U., Ryan, N., Flynn, C., \& Moreci, P. (1997). The revised schedule for affective disorders and schizophrenia for school aged children: present and lifetime version: preliminary reliability and validity data, Journal of the American Academy of Child and Adolescent Psychiatry, 36, 980-988.

Keenan, K., \& Wakschlag, L.S. (2002). Can a valid diagnosis of disruptive behavior disorder be made in preschool children?, American Journal of Psychiatry, 159, 351-358.

Nicholson, B.C., Fox, R.A., \& Johnson, S.D. (2005). Parenting young children with challenging behaviour, Infant and Child Development, 14, 425428.

Rockhill, C.M., Collett, B.R., McClellan, J.M., \& Speltz, M.L. (2006). Oppositional defiant disorder, in: J.L. Luby (Ed.) Handbook of preschool mental health: development, disorders, and treatment (New York, Guildford), 80-114.

Thomas, A., \& Chess, S. (1977). Temperament and development (Oxford, Brunner/Mazel).

Tucker, M.A., \& Fox, R.A. (1995). Assessment of families with mildly handicapped and nonhandicapped preschoolers, Journal of School Psychology, 33, 29-37.

\section{Appendix}

Table 1. Raw scores from self-report and observational measures completed during the intake evaluation.

\begin{tabular}{|c|c|c|}
\hline Measure & Mean & Standard deviation \\
\hline \multicolumn{3}{|l|}{ Eyberg Child Behavior Inventory } \\
\hline Intensity & 158.03 & 34.08 \\
\hline Problem & 18.75 & 7.77 \\
\hline \multicolumn{3}{|l|}{ Parent Behavior Checklist } \\
\hline Expectations & 30.95 & 8.61 \\
\hline Discipline & 14.64 & 4.20 \\
\hline Nurturing & 31.19 & 5.45 \\
\hline Parent-Child Relationship Scale & 52.50 & 15.21 \\
\hline
\end{tabular}

Early Child Development and Care, Vol. 179, No. 1 (2009): pg. 87-92. DOI. This article is (C) Taylor \& Francis (Routledge) and permission has been granted for this version to appear in e-Publications@Marquette. Taylor \& Francis (Routledge) does not grant permission for this article to be further copied/distributed or hosted elsewhere without the express permission from Taylor \& Francis (Routledge). 